significantly during exercise. Most patients are treated early for thyrotoxicosis due to other symptoms and this abnormality goes undetected unless specifically sought for. A few patients, particularly in the older age group, may present with predominant cardiac symptoms and a picture of dilated cardiomyopathy with or without atrial fibrillation and history of significant weight loss. The cause of this cardiomyopathy is not clear. Either thyrotoxicosis lowers the threshold for development of cardiomyopathy or it may be a direct effect of increased thyroid hormone. It is important to appreciate that thyrotoxicosis can lead to dilated cardiomyopathy which is partly or fully reversible.

1 Woeber KA. Thyrotoxicosis and heart failure. $N$ Engl $\mathcal{F}$ Med 1992; 327: 94-8.

2 Burckhardt D, Staub JJ, Kraenzlin M, Raeder E, Engel U, Cloppenburg $P$. The systolic time intervals in thyroid dysfunction. Am Heart $\mathcal{f}$ 1978; 95: 187-96.

3 Cohen MW, Sculman IC, Spenillo A, Surks MI. Effects of thyroid hormone on left ventricular function in patients treated for thyrotoxicosis. Am $\mathcal{F}$ Cardiol 1981; 48: 33-8.
Idiopathic dilated cardiomyopathy is very common. But before diagnosing such a disease which has no definitive treatment and a dismal prognosis one must make a sincere effort to find any treatable cause that can masquerade as dilated cardiomyopathy.

\section{Final diagnosis}

Thyrotoxic dilated cardiomyopathy (reversible).

Keywords: thyrotoxic cardiomyopathy, congestive heart failure

4 Forfar JC, Muir AL, Sauvers SA, Toft AD. Abnormal left ventricular function in hyperthyroidism. Evidence for a possible reversible cardiomyopathy. N Engl f Med 1982; 307: $1165-70$.

5 Safirstein SM, Santana O, Agasten A. Thyrotoxicosis associated with reversible cardiomyopathy. Am Heart $\mathcal{f}$
1994; 128: $616-7$.

\title{
Cortical blindness in a 35-year-old man
}

\author{
C Rickards, DI Shepherd
}

A 35-year-old man presented with a three-month history of increasing tunnel vision which had progressed to complete blindness. There was also a two-week history of progressive left-sided weakness. Examination revealed cortical blindness, left hemiparesis and crusted impetigo around the mouth. A computed tomography (CT) scan performed 12 weeks after the onset of his visual symptoms is shown below. His full blood count was normal except for an absolute lymphocyte count of $0.7 \times 10^{6} / 1$ (normal range 1.5 to 4 ). Liver function tests were mildly abnormal.

\section{Department of Neurology, North Manchester General Hospital, Crumpsall, Manchester M8 6RB, UK \\ C Rickards \\ DI Shepherd}

Accepted 1 June 1995

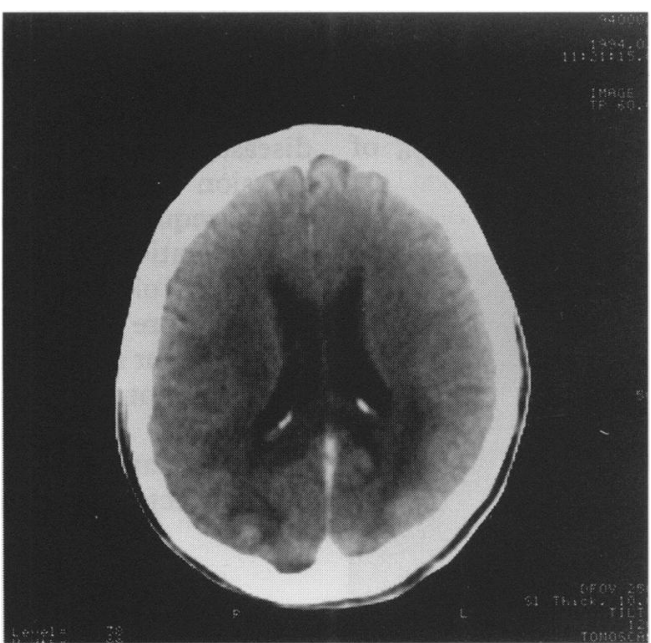

Figure 1 Contrast CT scan showing low attenuation in the white matter of the posterior hemispheres. There is no significant enhancement and no mass effect.

\section{Questions}

1 Name three causes of cortical blindness?

2 What is the most likely underlying diagnosis?

3 What two further investigations are indicated? 


\section{Answers}

QUESTION 1

Cortical blindness refers to visual failure in the presence of normal fundoscopy and normal pupillary light reactions. It implies bilateral disease affecting the optic radiations or occipital lobes. Anton's syndrome refers to the tendency of some cortically blind patients to deny their visual disability and to confabulate, eg, to give a confident but totally incorrect description of the examiner. Occipital lobe ischaemia (including watershed infarction), infiltrating glioma, and trauma are wellrecognised causes of cortical blindness. Cortical blindness can be difficult to distinguish from hysteria.

QUESTION 2

There are pointers to an underlying systemic illness: low lymphocyte count, abnormal liver function tests and the impetigo. The low density CT lesions and clinical evidence of progressive cortical dysfunction are entirely consistent with a diagnosis of progressive multifocal leukoencephalopathy, an infection which occurs in the context of impaired cellmediated immunity.

\section{QUESTION 3}

Further tests would include cerebrospinal fluid (CSF) examination, magnetic resonance imaging (MRI) and a search for a cause of immunosuppression (CD4:CD8 ratio, HIV status, investigation for lymphoproliferative disorder or malignancy). A definitive diagnosis would depend upon biopsy or CSF polymerase chain reaction to detect JC virus DNA.

Our patient was HIV-antibody positive with a CD4:CD8 ratio of 0.31 (normal range $1.2-3.0)$. His CSF was entirely normal. The MRI scan (figure 2) provided strong support of the diagnosis of progressive multifocal leukoencephalopathy.

\section{Discussion}

Progressive multifocal leukoencephalopathy is estimated to occur in approximately $4 \%$ of

Figure 2 T2 weighted MRI showing extensive areas of increased signal in white matter of both occipital regions which extends forward into the parietal region on the right side.

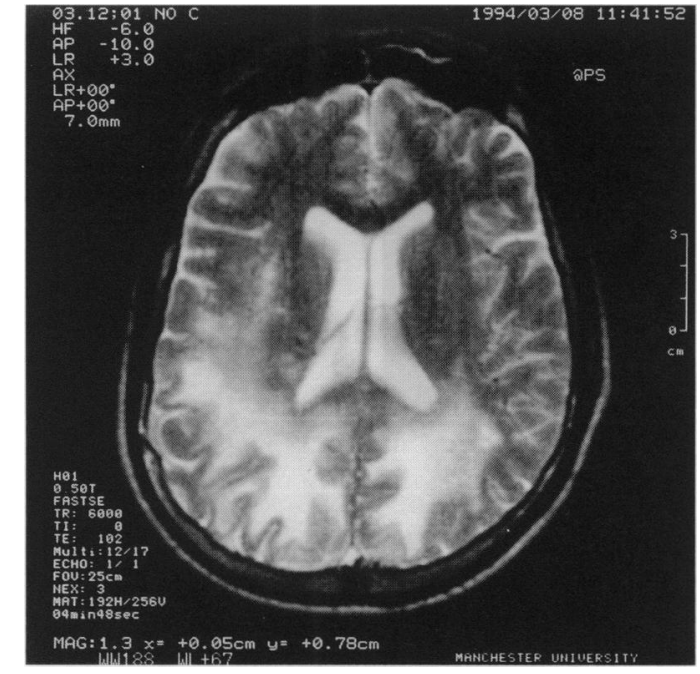

\section{Causes of cortical blindness}

- vascular: bilateral occipital lobe ischaemia ${ }^{\star}$ haemorrhages, cerebral vasculitis, air embolism, cortical venous thrombosis

- tumour: infiltrating glioma, occipital meningioma

- trauma: contre coup after frontal trauma

- degenerative: Creutzfeldt-Jakob, progressive multifocal leukoencephalopathy, Schilder's disease

${ }^{\star}$ most common cause of cortical blindness is hypoxia of striate cortex

Box 1

\begin{tabular}{l} 
Progressive multifocal \\
leukoencephalopathy: features \\
\hline - progressive cerebral dysfunction \\
- immunodeficient patient \\
- low density CT lesions \\
\hline
\end{tabular}

Box 2

HIV infected individuals ${ }^{1}$ and can represent the first clinical manifestation of previously undiagnosed $\mathrm{HIV}$ infection. ${ }^{2}$ In a patient without known immunodeficiency (eg, Hodgkin's, immunosuppressive treatment), HIV would be the most likely cause. ${ }^{3}$ The clinical picture is varied but involves progressive cerebral dysfunction which typically reflects rather focal pathology, eg, hemiparesis, ataxia, hemianopia. However, more general cerebral symptoms may be prominent, eg, cognitive decline and headache. Overall, the commonest signs in progressive multifocal leukoencephalopathy are spastic hemiparesis, altered mentation and visual field loss.

Progressive multifocal leukoencephalopathy is caused by a papovavirus known as JC virus (not to be confused with Jakob-Creutzfeldt disease). Diagnosis often depends upon a high index of suspicion as the neurological syndrome can be wrongly ascribed to the primary disease, eg, HIV encephalopathy or CNS invasion by lymphoma. ${ }^{3}$ The definitive diagnosis requires histological confirmation of demyelination and characteristic inclusion bodies in oligodendrocytes. In HIV-related cases there may also be appreciable mononuclear cell infiltration. ${ }^{4}$ Antibodies to JC virus are not particularly useful as titres are similar in progressive multifocal leukoencephalopathy-infected individuals and control subjects, suggesting that some cases of

\begin{tabular}{|l|}
\hline $\begin{array}{l}\text { Progressive multifocal } \\
\text { leukoencephalopathy: diagnosis }\end{array}$ \\
\hline - clinical with supportive radiology \\
- histological \\
- CSF polymerase chain reaction \\
\hline
\end{tabular}




\begin{tabular}{|l|}
\hline Progressive multifocal \\
leukoencephalopathy: differential \\
diagnosis in HIV \\
\hline - lymphoma \\
- toxoplasmosis \\
- HIV encephalopathy \\
\hline
\end{tabular}

Box 4

progressive multifocal leukoencephalopathy may result from reactivation of an otherwise dormant infection. ${ }^{2}$ In practice, the clinical picture with supportive radiological evidence is usually sufficient for diagnosis. ${ }^{2}$ The characteristic radiological changes ${ }^{1,3}$ of progressive multifocal leukoencephalopathy are nonenhancing, low density CT lesions without mass effect. These lesions are high signal on T2-weighted MRI. Clinical features at presentation are typically far more striking than the more subtle CT scan changes. ${ }^{3}$ Routine CSF microscopy and biochemistry are usually normal or may show only non-specific changes. ${ }^{1}$ Recent work suggests that the polymerase chain reaction to identify JC virus DNA in CSF is a highly specific and moderately sensitive technique for positive diagnosis without the need for biopsy. ${ }^{5}$

In HIV-infected patients the diagnosis of progressive multifocal leukoencephalopathy

1 Berger JR, Kaszovitz B, Donovan-Post J, Dickinson G. Progressive multifocal leukoencephalopathy associated with human immunodeficiency virus infection. Ann Intern Med human immunodefici

2 Gillespie SM, Chang Y, Lemp G, et al. Progressive multifocal leukoencephalopathy in persons infected with human tifocal leukoencephalopathy in persons infected with human immunodeficiency virus, San

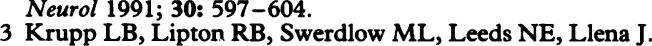

Krupp LB, Lipton RB, Swerdlow ML, Leeds NE, Llena J.
Progressive multifocal leukoencephalopathy: clinical and radiological features. Ann Neur 1985; 17: 344-9. without pathological/polymerase chain reaction confirmation demands exclusion of alternative diagnosis (principally toxoplasmosis, HIV encephalopathy and CNS lymphoma). HIV encephalopathy (AIDS dementia complex) does not usually produce focal signs and the other two disease processes are associated with ring-enhancing lesions on neuroimaging. However, as toxoplasmosis responds relatively well to treatment, HIV-positive patients with presumptive progressive multifocal leukoencephalopathy are often given a course of pyrimethamine and sulfadiazine so that treatable pathology is not overlooked.

There is no useful treatment for progressive multifocal leukoencephalopathy and the prognosis is poor, patients rarely surviving more than a few months. ${ }^{1}$ Even in the absence of known HIV infection and/or risk factors the possibility of an HIV-related illness should be considered early in the work up of patients with unusual neurological disease. Once HIVrelated CNS disease has been diagnosed prompt investigation is essential.

\section{Final diagnosis}

Progressive multifocal leukoencephalopathy presenting as cortical blindness in a patient with AIDS

Keywords: progressive multifocal leukoencephalopathy, cortical blindness, AIDS, MRI

4 Hair LS, Nuovo G, Powers JM, Sisti MB, Britton CB, Miller JR. Progressive multifocal leukoencephalopathy in patients with HIV. Hum Pathol 1992; 23: 663-7.

5 Weber T, Turner RW, Frye S, et al. Specific diagnosis of progressive multifocal leukoencephalopathy by the polymerase chain reaction. $\mathcal{F}$ Infect Dis 1994; 169: 1138-41.

\title{
The post-traumatic painful testis
}

\author{
FI Chinegwundoh
}

North Staffs Hospital Trust, Stoke on Trent, UK

FI Chinegwundoh

Correspondence address Department of Urology, Royal Shrewsbury Hospitals, North Mytton Oak Road, Shrewsbury SY3 8XH, UK

Accepted 28 June 1995
A 13-year-old schoolboy presented to the Accident and Emergency department having awoken with marked left testicular pain and vomiting. The previous day he had suffered a blow to his scrotum whilst engaged in a sporting activity. The immediate discomfort was insufficient for him to seek medical attention. A month previously he had experienced a short-lived episode of left scrotal pain. Examination revealed a hard, tender left scrotal swelling.

\section{Questions}

1 Suggest two differential diagnoses?

2 Which investigation may help in the diagnosis?

3 What is the treatment of the condition? 